\title{
Eucalyptus Oil-Mediated Synthesis of Gold Nanoparticles
}

\author{
Anderson Thesing ${ }^{1}$, José E. R. do Nascimento ${ }^{2}$, Raquel G. Jacob ${ }^{2}$ and Jacqueline F. L. Santos ${ }^{1}$ \\ 1. LAMAI, Instituto de Química, Universidade Federal do Rio Grande do Sul, Porto Alegre 91501-970, Brazil \\ 2. LASOL, Centro de Ciências Químicas, Farmacêuticas e de Alimentos, Universidade Federal de Pelotas, Capão do Leão \\ 96010-900, Brazil
}

\begin{abstract}
The search for efficient methods for the synthesis of metal nanoparticles has been widely explored. Within this context, the use of biological materials such as plants, algae, bacteria and fungi has been reported to various metal nanoparticles as an efficient, low-cost and environmental friendly approach. In this paper we present a single-step method for synthesizing gold nanoparticles, by using essential oils from Brazilian Eucalyptus leaves (urograndis and dunnii). The results strongly suggest that the presence of a stronger bioreducing agent, $\alpha$-Terpinyl acetate, in the Eucalyptus urograndis, results in higher antioxidant capacity and hence in the synthesis of gold nanoparticles with more controlled size distribution.
\end{abstract}

Key words: Nanoparticles, essential oils, biosynthesis.

\section{Introduction}

The synthesis and application of metal nanoparticles has been the subject of intense research for over two decades [1, 2]. In the search for efficient, low cost and eco-friendly approaches to obtain metal nanoparticles with controlled shape and size, many research groups have devoted their efforts to a large variety of physical, chemical and more recently biological methods [3]. Due to the growing environmental and health awareness, the demand for eco-friendly methods to obtain all sorts of materials, has driven the research in many areas. Especially concerning nanotechnology, that is an important issue once metal nanoparticle such as silver has been widely applied in products that are directly exposed to the human body, conveyed by cosmetic and pharmaceutical materials [4]. Within this context, the use of biological materials, such as plants, algae, bacteria and fungi comes to light as a very interesting alternative to obtain nanoparticles through

Corresponding author: Anderson Thesing, PhD student, research fields: materials science, nanostructured materials. environmentally friendly approaches. The synthesized nanoparticles can present a combination of effects from the metal core and the stabilizing shell, once the media used to promote the bioreduction of the metallic precursor can also act as stabilizing layer on the synthesized nanoparticles [5, 6].

Among the biological materials, the ones obtained from plants present an advantage of abundance, which is a major advantage concerning large scale production. Essential oils can be found in more than 5,000 species in the Myrtaceae family alone [7]. Only considering Eucalyptus, which is a member of the Myrtaceae family, more than 700 species of Eucalyptus can be found around the world [8]. In addition to present antimicrobial properties, essential oils extracted from the leaves of Eucalyptus present antioxidant properties, which is a result of their ability to inhibit or delay oxidation process by blocking the initiation or propagation of the oxidizing reactions. These properties are important concerning application in different areas, including biomedical, nutrition and agrochemical, as these essential oils can avoid oxidative deterioration of food products as well as several human diseases. In 
the human body, these molecules may enhance the immune defense and lower the risk of cancer and degenerative diseases [9-14].

Essential oils have a complex composition, containing from a dozen to several hundred components, in the case of Eucalyptus essential oils, the main components are monoterpenes and sesquiterpenes. Approximately $44 \%-84 \%$ of the oil comprises 1,8-cineole, and this composition depends on the species. These oils also contain minor amount of $\alpha$-pinene, a monoterpene compound which is reported to have a wide range of biological activities [15-17], i.e. antioxidant, anticancer and genotoxic activities [18].

The literature describes many different approaches to evaluate the antioxidant activity of essential oils [19-22]. The most well-known methods are based on single electron transfer, hydrogen atom transfer, cupric reducing antioxidant capacity and ferric reducing antioxidant power [23, 24]. An alternative method that has been explored consists on the reduction of metallic cations, resulting in the formation of nanoparticles with plasmonic properties $[10,25]$. Hence, different research groups have explored essential oils and reduction media to promote the synthesis of metallic nanoparticles [6]. The biosynthesis of metallic nanoparticles by using essential oils has additional interests as the different antioxidant capabilities and structures of the oils may tune their unusual optical and surface properties, allowing application in different areas, as catalysis, solar cell and biosensors [26-33].

In this paper, we show a simple method for synthesizing gold nanoparticles (AuNP) by using essential oils (EOs) from Brazilian Eucalyptus plant using two different EOs extracted from Eucalyptus urograndis and Eucalyptus dunnii (E. urograndis and E. dunnii) leaves. This one-step methodology was based on the ability of antioxidant properties of natural resources to reduce gold ions, forming AuNP. The EOs were characterized with FTIR, GC-MS and cyclic voltammetry. The AuNPs were characterized with UV-Vis spectroscopy.

\section{Experimental}

\subsection{Chemicals}

Potassium chloride, chloroauric acid and methanol were purchased from Sigma. E. dunnii and E. urograndis plants were grown in Herval, a city located in southern Brazil (RS, latitude $32^{\circ} 01^{\prime} \mathrm{S}$ and longitude $\left.53^{\circ} 23^{\prime} \mathrm{O}\right)$ at $287 \mathrm{~m}$ above sea level. The harvesting of the aerial parts of E. urograndis and E. dunnii plants occurred in the morning of May 2010. Ultrapure water was obtained by Millipore Direct Q ${ }^{\circledR} 3$ UV and was used in all experiments.

\subsection{Extraction of Essential Oils}

Eucalyptus leaves were dried in a controlled environment at temperature of $25{ }^{\circ} \mathrm{C}$, during seven days. $500 \mathrm{~g}$ (dry weight) of dry leaves was cut into small pieces, and the EO was extracted by steam distillation for $2.5 \mathrm{~h}$ using a portable, $1 \mathrm{~kg} \cdot \mathrm{batch}^{-1}$ capacity, mini distillation apparatus (Model:Linax-D1). The distillate was extracted with dichloromethane, following by drying over anhydrous sodium sulfate and evaporating the solvent $\left(30{ }^{\circ} \mathrm{C}\right)$ at reduced pressure. The experiment was performed in triplicate, and the EOs yields were then estimated based on the dry weights (DW). The yields were expressed as a percentage $(\mathrm{w} / \mathrm{w})$ and the EOs were stored at $10{ }^{\circ} \mathrm{C}$.

\subsection{Characterization of Essential Oils}

The EOs were analyzed by a gas chromatograph coupled to a mass spectrometer (GC-MS) using a Shimadzu GC-MS QP2010 with electron impact ionization $(70 \mathrm{eV})$. An RTx-5 fused silica capillary column $(30 \mathrm{~m} \times 0.25 \mathrm{~mm} \times 0.25 \mu \mathrm{m}$ coated with $5 \%$ phenyl group silicone, $95 \%$ dimethylpolysiloxane, and $0.25 \mu \mathrm{m}$-thick film) was used. The oven temperature was programmed to rise from 60 to $220^{\circ} \mathrm{C}$ at a rate of $4{ }^{\circ} \mathrm{C} \cdot \min ^{-1}$, helium was used as the carrier gas at a flow rate of $0.8 \mathrm{~mL} \cdot \mathrm{min}^{-1}$. The EOs components from 
E. dunnii and E. urograndis leaves were identified by comparing their mass spectra with those stored in the NIST/EPA/NIH library and by comparing Kovats retention indices (KI) from literature [34]. The Kovats indices of the oil constituents were determined comparing to (C8-20 and C10) n-alkane standard by using an EO solution dissolved in hexane.

\subsection{Chemicals Composition of Essential Oils}

The EOs obtained from E. dunnii and E. urograndis leaves were obtained with yields of $1.14 \%(\mathrm{w} / \mathrm{w})$ and $0.56 \%(\mathrm{w} / \mathrm{w})$, respectively, after steam distillation. The GC-MS analysis resulted in the identification of 18 constituents in the oil from E. dunnii eluted between 4.67 and $23.95 \mathrm{~min}$, representing $100 \%$ of the EO. In E. urograndis, 16 oil constituents were identified between 4.68 and $23.95 \mathrm{~min}$, representing $100 \%$ of the total. The oils from both plants consisted mostly of monoterpenes, sesquiterpenes and oxygenated sesquiterpenes. Table 1 describes the primary chemical constituents of the EOs from $E$. dunnii and E. urograndis, respectively. 1,8-cineole $(33.06 \%$ and $41.41 \%)$ and $\alpha$-pinene $(18.30 \%$ and $30.07 \%$ ) were the major constituents of the E. dunnii and E. urograndis EOs, respectively. $\alpha$-Terpinyl acetate $(9.56 \%)$ was also identified in the $E$. urograndis $\mathrm{EO}$.

Table 1 Chemical composition of EO from $E$. dunnii and e-urograndis.

\begin{tabular}{|c|c|c|c|c|c|c|}
\hline \multirow{2}{*}{ Compounds $^{\mathrm{a}}$} & \multicolumn{3}{|c|}{ E. dunnii } & \multicolumn{3}{|c|}{ E. urograndis } \\
\hline & Comp. (\%) & $\mathrm{KI}^{\mathrm{b}}$ & KI Adams $^{c}$ & Comp. (\%) & $\mathrm{KI}^{\mathrm{b}}$ & $\mathrm{KI}$ Adams ${ }^{\mathrm{c}}$ \\
\hline$\alpha$-Pinene & 18.30 & 934 & 939 & 30.07 & 934 & 939 \\
\hline Camphene & - & - & - & 0.51 & 950 & 953 \\
\hline$\beta$-Pinene & 0.78 & 978 & 980 & - & - & - \\
\hline Sabinene & - & - & - & 0.18 & 976 & 976 \\
\hline Myrcene & 0.92 & 991 & 991 & - & - & - \\
\hline$\alpha$-Phellandrene & 1.12 & 1,006 & 1,005 & - & - & - \\
\hline o-Cymene & 2.38 & 1,025 & 1,022 & 2.85 & 1,025 & 1,022 \\
\hline Limonene & 7.58 & 1,029 & 1,031 & 8.13 & 1,029 & 1,031 \\
\hline 1,8-Cineole & 33.06 & 1,032 & 1,033 & 41.41 & 1,032 & 1,033 \\
\hline (Z)- $\beta$-ocimene & 1.61 & 1,036 & 1,040 & - & - & - \\
\hline (E)- $\beta$-ocimene & 0.23 & 1,047 & 1,050 & - & - & - \\
\hline$\gamma$-terpinene & 1.45 & 1,059 & 1,062 & - & - & - \\
\hline$\alpha$-Pinene oxide & - & - & - & 0.43 & 1,105 & 1,095 \\
\hline 2-Norbornanol & - & - & - & 0.25 & 1,115 & 1,112 \\
\hline Campholenal & - & - & - & 0.29 & 1,127 & 1,125 \\
\hline Borneol & - & - & - & 1.07 & 1,168 & 1,165 \\
\hline Terpin-4-ol & 0.50 & 1,179 & 1,177 & - & - & - \\
\hline$\alpha$-terpineol & 10.50 & 1,192 & 1,189 & 3.02 & 1,192 & 1,189 \\
\hline$\alpha$-Terpinyl acetate & - & - & - & 9.56 & 1,352 & 1,350 \\
\hline$\alpha$-Gurjunene & 2.56 & 1,413 & 1,409 & - & - & - \\
\hline Nopyl acetate & - & - & - & 0.24 & 1,423 & 1,424 \\
\hline Aromadendrene & 10.35 & 1,442 & 1,439 & 0.62 & 1,443 & 1,439 \\
\hline Allo-aromadendrene & 1.96 & 1,464 & 1,461 & - & - & - \\
\hline Viridiflorene & 1.59 & 1,498 & 1,493 & - & - & - \\
\hline Ledol & 0.99 & 1,564 & 1,565 & - & - & - \\
\hline Spathulenol & - & - & - & 0.72 & 1,582 & 1,576 \\
\hline Viridiflorol & 4.12 & 1,588 & 1,590 & 0.65 & 1,588 & 1,590 \\
\hline
\end{tabular}

${ }^{\mathrm{a}}$ Compounds listed in order of elution; ${ }^{\mathrm{b}} \mathrm{KI}=$ Kovats Indices calculated; ${ }^{\mathrm{c}} \mathrm{KI}$ of literature (ADAMS, 1995). 

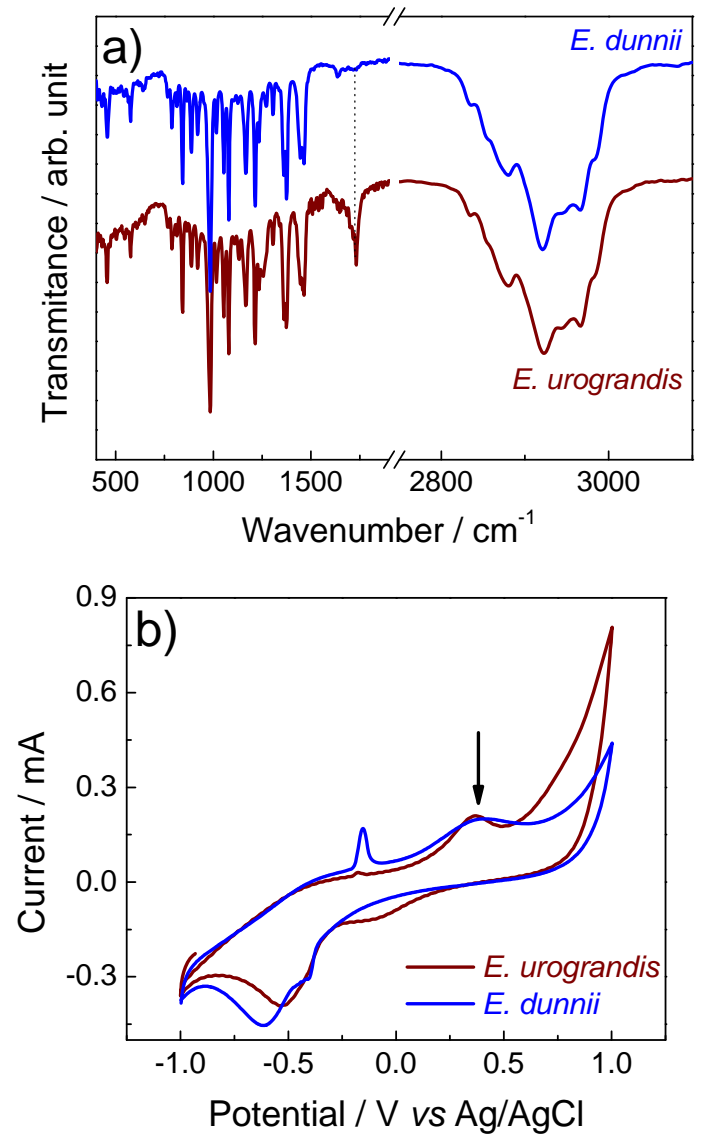

Fig. 1 (a) FTIR spectra of E. urograndis and E. dunnii EOs according to GC-MS analysis; (b) Cyclic voltammograms of $E$. urograndis $(20 \mu \mathrm{L})$ and $E$. dunnii $(60 \mu \mathrm{L})$ extracts in $\mathrm{KCl}\left(0.1 \mathrm{~mol} \cdot \mathrm{L}^{-1}\right)$. Scan rate $20 \mathrm{mV} \cdot \mathrm{s}^{-1}$.

\subsection{Biosynthesis of gold Nanoparticles Using} Essential Oils

Tests were performed by diluting $3.5 \mu \mathrm{L}$ of chloroauric acid and $80 \mu \mathrm{L}$ of the methanolic (1:1, v:v) EO solution (E. urograndis or E. dunnii) in $10 \mathrm{~mL}$ of ultrapure water. The resulted solution was kept under stirring and heated at $45{ }^{\circ} \mathrm{C}$ until the coloring changing from colorless to red wine, indicating the formation of AuNP. The change in color was observed within 15 min.

\subsection{Apparatus}

Infrared spectra within the range of 4,000-475 $\mathrm{cm}^{-1}$ in attenuated total reflection mode (FTIR ATR), were obtained using an FTIR Bruker Alpha-P spectrometer.
All voltammograms were carried out at room temperature using a classical three-electrode cell connected to a potentiostat/galvanostat AUTOLAB $302 \mathrm{~N}$. The electrolyte solution was prepared by adding $20 \mu \mathrm{L}$ of a methanolic solution of $E$. urograndis $(1: 1, \mathrm{v}: \mathrm{v})$ in $25 \mathrm{~mL}$ of $\mathrm{KCl}\left(0.1 \mathrm{~mol} \cdot \mathrm{L}^{-1}\right)$. For the E. dunnii extract it was necessary an electrolyte three times more concentrated to observe the anodic and cathodic peak. Therefore $60 \mu \mathrm{L}$ of a methanolic solution of $E$. dunnii extract $(1: 1, \mathrm{v}: \mathrm{v})$ was used to prepare the electrolyte in this case. The voltammograms were acquired in a potential range from -1.0 to $+1.0 \mathrm{~V}$ at a scan rate of $20 \mathrm{mV} \cdot \mathrm{s}^{-1}$, using $\mathrm{Ag} / \mathrm{AgCl}$ as reference electrode and a platinum plate as working electrode and counter electrode. Synthesis of AuNP was monitored by UV-Vis spectroscopy using a Shimadzu UV-2425 spectrophotometer. The extinction spectra were recorded ranging from 475 to $800 \mathrm{~nm}$.

\section{Results and Discussion}

\subsection{Characterization of Essential Oils}

FTIR spectra of the EOs E. urograndis and E. dunnii are displayed in Fig. 1a. As one can observe both EOs present similar vibrational bands characteristic of terpenes, which is the major component of both oils. The main difference between the FTIR spectra is a vibrational band at $c a$. 1,750 $\mathrm{cm}^{-1}$ assigned to the stretch of carbonyl groups of ester present in $\alpha$-Terpinyl acetate (axial deformation of the bond) [35]. This compound is absent in E. dunnii, although it is one of the major compounds in $E$. urograndis, as one can see in Table 1.

The carbonyl groups may increase the antioxidant activity of the EO E. urograndis due to the high electronic density present in this group. In addition, the presence of this functional group in the molecular structure may allow higher stabilization of the nanoparticle due to electrostatic interactions. All these characteristics favour the formation of nanoparticles 
with high stability, tuneable optical properties and pre-modified surface, allowing different applications.

In order to compare the redox properties of the EOs, cyclic voltammograms were obtained from $E$. urograndis and E. dunnii in the electrolyte solution (Fig. 1b). As one can see, the anodic potential is almost the same for E. urograndis $(c a .0 .37 \mathrm{~V})$ and $E$. dunnii (ca. $0.41 \mathrm{~V}$ ) and is close to others natural organic extracts described in the literature that also presented antioxidant activity [6]. However, a narrower anodic peak is observed for E. urograndis, and it is important to keep in mind the concentration of the EO in the electrolyte solution, E. urograndis is three times more diluted than E. dunnii electrolyte solution. These observations suggest a better antioxidant capability for E. urograndis, and a mechanism for electrons transfer evolving a lower variety of chemical species.

\subsection{Biosynthesis of Gold Nanoparticles}

The antioxidant property of the EOs was evaluated by probing their ability to promote the bioreduction of gold precursor. The formation of AuNP is easily monitored by colour changing of the solution from colorless to reddish, therefore optical measurements is a simple way to characterize the formation of AuNP $[32,36]$. The extinction spectra obtained from colloidal solution of AuNP synthesized by reducing $\mathrm{Au}^{3+}$ cations with E. urograndis or E. dunnii EOs presented very distinct bands (Fig. 2a). These maximum extinction bands are assigned to the localized plasmonic excitation (resonance oscillation between electrons and incident light) and light scattering of AuNP (no extinction band was observed from the solution previously the synthesis) [36].

The presence and position of these bands are strongly dependent on shape, morphology and size distribution of the nanoparticles. For spherical AuNP a plasmonic absorption band is observed around 520-580 nm. In smaller nanoparticles $(<2 \mathrm{~nm})$

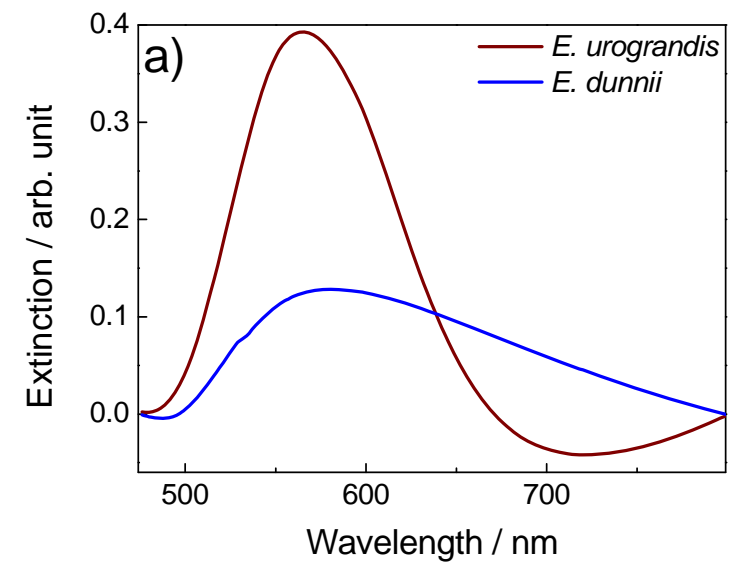

(a)

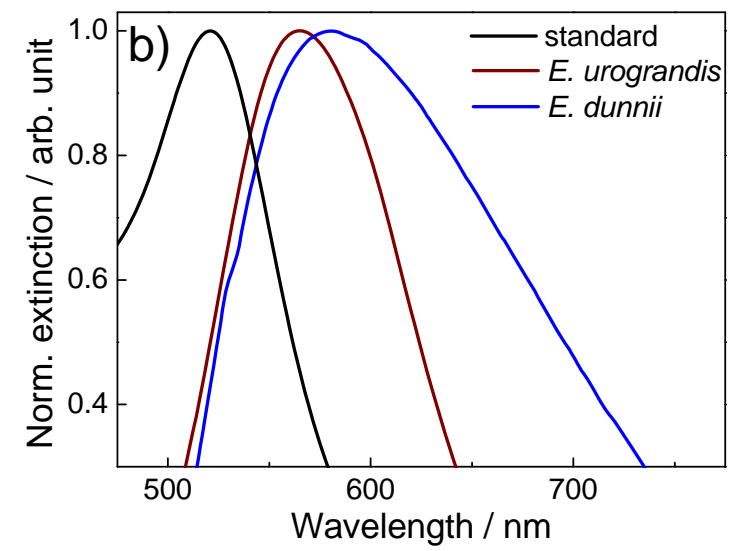

(b)

Fig. 2 (a) UV-Vis extinction spectra of colloidal AuNP solution synthesized with $E$. urograndis and E. dunnii EOs; (b) Normalized UV-Vis extinction spectra of AuNP synthesized with EOs and by conventional method (named standard).

predominates quantum size effects presenting electronic properties of free electrons rather than electronic transitions from band to band or level to level. In larger nanoparticles $(>2 \mathrm{~nm})$ the electronic effects (oscillating electrons) give rise to the localized plasmonic surface resonance described by Mie, Maxwell-Garnett and Drude theories and modeled by discrete dipole approximations (DDA) [37, 38].

The extinction bands at around 566 and $580 \mathrm{~nm}$ (Fig. 2) for AuNP synthesized with E. urograndis and E. dunnii EOs, respectively, are red-shifted related to AuNP synthesized with an conventional method (Fig. 2b) [32, 39], suggesting the formation of larger spherical nanoparticles with different sizes distribution and population [40-42]. In addition to the 
band position, other divergences were also observed in the plasmonic band, such as intensity (3 times higher to E. urograndis) and full width at half maximum (FWHM, ca. 103 and $171 \mathrm{~nm}$ for E. urograndis and E. dunnii, respectively). These results suggest that $E$. urograndis presents better antioxidant capacity, leading to a high population of AuNP with lower size distribution. We assume that the mechanism for the growth and stabilization for the AuNP is guided by the higher antioxidant activity of $E$. urograndis $\mathrm{EO}$, once this enlargement was not observed for E. dunnii. The highest capability of reducing $\mathrm{Au}^{3+}$ to $\mathrm{Au}^{0}$ was previously related to the highest antioxidant activities of flavonoids and phenolic acids [43].

These results are in accordance with the electrochemical analysis, suggesting a better antioxidant activity to E. urograndis. The compositions of the EOs suggest a higher antioxidant activity due to the higher concentration of terpenes (a difference of $c a$. $20 \%$ ), such as $\alpha$-pinene and 1,8-cineole, in addition to the presence of $\alpha$-Terpinyl acetate. These compounds may have a crucial role in the mechanism for nucleation and stabilization of AuNP. A mechanism was proposed by Singh et al. for the growth of AuNP by oxidation of 1,8-cineole, where $\mathrm{Cl}$ from $\mathrm{AuCl}_{4}^{-}$ reacts with $\alpha-\mathrm{H}$ of 1,8 -cineole. Next, oxygen in water molecule (solvent) reacts with $\mathrm{Au}^{3+}$ bond in 1,8-cineole, leading to an Au-O bond. Following, - $-\mathrm{OH}$ bond in the ring attacks on $\mathrm{C}$, giving its bond pair to $\mathrm{Au}$, reducing $\mathrm{Au}^{3+}$ to $\mathrm{Au}^{0}$. As consequence a $\mathrm{C}=\mathrm{O}$ bond is formed [44]. Therefore, both, the molecular structure and the amount of the major component are responsible for the higher antioxidant capacity of $E$. urograndis compared to E. dunnii.

One of the main advantages of the proposed methodology is that using the extract from the leaves of Eucalyptus due to the simplicity compared to methodologies where the whole extract or plant tissue is used; in addition, the methodology is readily scalable and relatively less expensive than methods based on microbial process [45-47].

\section{Conclusion}

AuNP were synthesized using reducing agents obtained from abundant natural resources available around the world. The source of the plant extract contains different concentrations and combinations of organic reducing agents, that may act both as reducing and stabilizing agents and therefore influence the characteristics of the nanoparticles. Using an EO containing high concentration of $\alpha$-terpinyl acetate resulted in narrower size distribution due to the fast nucleation process. Once narrow size distribution of nanoparticles is fundamental for applications we believe this work will be helpful for the scientific community. In addition, the proposed methodology is simple with a low cost allowing obtaining the AuNP with a single-step environmentally friendly method, as the synthesis is rapidly performed at low temperature using no harmful chemicals.

\section{Acknowledgments}

Authors are thankful to FAPERGS (PRONEM 11/2026-4) and CNPq (process 423244/2016-7 and 303439/2015-7). The students thank CAPES and CNPq for the scholarships.

\section{References}

[1] Brolo, A. G. 2012. "Plasmonics for Future Biosensors." Nat. Photonics 6: 709-13.

[2] Santos, J. F. L., Santos, M. J. L., Thesing, A., Tavares, F., Griep, J., and Flores, M. R. 2016. "Localized Surface Plasmon Resonance Applied to Biosensors and Solar Cells." Quim. Nova 39: 1098-111.

[3] El-Refai, A. A., Ghoniem, G. A., El-Khateeb, A. Y., and Hassaan, M. M. 2018. "Eco-Friendly Synthesis of Metal Nanoparticles Using Ginger and Garlic Extracts as Biocompatible Novel Antioxidant and Antimicrobial Agents" J. Nanostructure Chem. 8: 71-81.

[4] Song, J. Y., Jang, H. K., and Kim, B. S. 2009. "Biological Synthesis of Gold Nanoparticles Using Magnolia Kobus and Diopyros Kaki Leaf Extracts." Process Biochem. 44: 1133-8.

[5] Hou, P., Liu, H., Li, J., and Yang, J. 2015. "One-Pot Synthesis of Noble Metal Nanoparticles with a Core-Shell Construction." Crys tEng Comm 17: 1826-32.

[6] Roy, N., Laskar, R. A., Sk, I., Kumari, D., Ghosh, T., and 
Begum, N. A. 2011. "A Detailed Study on the Antioxidant Activity of the Stem Bark of Dalbergia sissoo Roxb., an Indian Medicinal Plant." Food Chem. 126: $1115-21$.

[7] Govaerts, R., Sobral, M., Ashton, P., and Barrie, F. 2008. World Checklist of Myrtaceae. Royal Botanic Gardens United States.

[8] Brooker, M. I. H., and Kleinig, D. A. 2006. Field Guide to Eucalyptus. Melbourne: South-Eastern Australia.

[9] Moon, J. K., and Shibamoto, T. 2009. "Antioxidant Assays for Plant and Food Components." J. Agric. Food Chem. 57: 1655-66.

[10] Banerjee, J., and Narendhirakannan, R. T. 2011. "Biosynthesis of Silver Nanoparticles from Syzygium cumini (L.) Seed Extract and Evaluation of TH.” Dig. J. Nanomater. Bios. 6: 961-8.

[11] Pham-Huy, L. A., He, H., and Pham-Huy, C. 2008. "Free Radicals, Antioxidants in Disease and Health." Int. J. Biomed. Sci. 4: 89-96.

[12] Percival, M. 1998. “Antioxidants.” Clin. Nutr. Insight 31: 1-4.

[13] Dipankar, C., and Murugan, S. 2012. "The Green Synthesis, Characterization and Evaluation of the Biological Activities of Silver Nanoparticles Synthesized from Iresine herbstii Leaf Aqueous Extracts." Colloid Surf. B: Biointerfaces 98: 112-9.

[14] Szydlowska-Czerniak, A., Tulodziecka, A., and Szlyk, E. 2012. “A Silver Nanoparticle-Based Method for Determination of Antioxidant Capacity of Rapeseed and Its Products." Analyst 137: 3750-9.

[15] Aydin, E., Türkez, H., and Geykoglu, F. 2013. "Antioxidative, Anticancer and Genotoxic Properties of a-Pinene on N2a Neuroblastoma Cells." Biologia 68: 1004-9.

[16] Wang, W., Wu, N., Zu, Y. G., and Fu, Y. J. 2008. "Antioxidative Activity of Rosmarinus officinalis L. Essential Oil Compared to Its Main Components." Food Chem. 108: 1019-22.

[17] Singh, H. P., Batish, D. R., Kaur, S., Arora, K., and Kohli, R. K. 2006. " $\alpha$-Pinene Inhibits Growth and Induces Oxidative Stress in Roots.” Ann. Bot. 98: 1261-9.

[18] Baser, K. H. C., and Buchbauer, G. 2010. Handbook of Essential Oils, Science, Technology and Applications, CRC Press United States.

[19] Mannino, S., Brenna, O., Buratti, S., and Cosio, M. S. 1998. "A New Method for the Evaluation of the 'Antioxidant Power' of Wines.” Electroanal. 10: 908-12.

[20] Arnao, M. B. 2000. "Some Methodological Problems in the Determination of Antioxidant Activity Using Chromogen Radicals: A Practical Case." Trends Food Sci. 11: 419-21.

[21] Blasco, A. J., Rogerio, M. C., Gonzalez, M. C., amd
Escarpa, A. 2005. “'Electrochemical Index” as a Screening Method to Determine 'Total Polyphenolics' in Foods: A Proposal.” Anal. Chim. Acta 539: 237-44.

[22] Ivekovic, D., Milardovic, S., Roboz, M., and Grabaric, B. S. 2005. "Evaluation of the Antioxidant Activity by Flow Injection Analysis Method with Electrochemically Generated ABTS Radical Cation.” Analyst 130: 708-714.

[23] Szydlowska-Czerniak, A., Trokowski, K., Karlovits, G., and Szlyk, E. 2010. "Determination of Antioxidant Capacity, Phenolic Acids, and Fatty Acid Composition of Rapeseed Varieties." J. Agric. Food Chem. 58: 7502-9.

[24] Szydlowska-Czerniak, A., Bartkowiak-Broda, I., Karlovi, I., Karlovits, G., and Szlyk, E. 2011. "Antioxidant Capacity, Total Phenolics, Glucosinolates and Colour Parameters of Rapeseed Cultivars." Food Chem. 127: 556-63.

[25] Wang, J., Zhou, N., Zhu, Z., Huang, J., and Li, G. 2007. "Detection of Flavonoids and Assay for Their Antioxidant Activity Based on Enlargement of Gold Nanoparticles." Anal. Bioanal. Chem. 388: 1199-205.

[26] Lewis, L. N. 1993. "Chemical Catalysis by Colloids and Clusters.” Chem. Rev. 93: 2693-730.

[27] Chan, W. C. W., and Nie, S. M. 1998. "Quantum Dot Bioconjugates for Ultrasensitive Nonisotopic Detection." Science 281: 2016-8.

[28] Haruta, M., and Daté, M. 2001. "Advances in the Catalysis of $\mathrm{Au}$ Nanoparticles." Appl. Catal. A 222: 427-37.

[29] Peña, S. R. N., Freeman, R. G., Reiss, B. D., He, L., Peña, D. J., Walton, I. D., Cromer, R., Keating, C. D., and Natan, M. J. 2001. "Submicrometer Metallic Barcodes." Science 294: 137-41.

[30] Aroca, R. F. 2013. "Plasmon Enhanced Spectroscopy." Phys. Chem. Chem. Phys. 15: 5355-66.

[31] Haes, A. J., and Van-Duyne, R. P. 2002. "A Nanoscale Optical Biosensor: Sensitivity and Selectivity of an Approach Based on the Localized Surface Plasmon Resonance Spectroscopy of Triangular Silver Nanoparticles." J. Am. Chem. Soc. 124: 10596-604.

[32] da Silva, A. L. C. M., Gutierres, M. G., Thesing, A., Lattuada, R. M., and Ferreira, J. 2014. "SPR Biosensors Based on Gold and Silver Nanoparticle Multilayer Films." J. Braz. Chem. Soc. 25: 928-34.

[33] Chaudhary, A., Khan, S., Gupta, A., and Nandi, C. K. 2016. "Effect of Surface Chemistry and Morphology of Gold Nanoparticle on the Structure and Activity of Common Blood Proteins." New J. Chem. 40: 4879-83.

[34] Adams, R. P. 2007. Identification of Essential Oils Components by Gas Chromatography/Mass Spectrometry New York: Allured Publ. Carol Stream.

[35] Pavia, D. L., Lampman, G. M., Kriz, G. S., and Vyvyan, 
J. R. 2015. Introduction to Spectroscopy, Stamford: Cengage Learning.

[36] Thesing, A., Loguercio, L. F., Santos, M. J. L., and Santos, J. F. L. 2016. "Simple Approach to Obtain a Localized Surface Plasmon Resonance Sensor Based on Poly(dimethylsiloxane)/Gold Nanoparticles Nanocomposite." J. Nanosci. Nanotechnol. 16: 10080-6.

[37] Moores, A., and Goettmann, F. 2006. "The Plasmon band in Noble Metal Nanoparticles: An Introduction to Theory and Applications." New J. Chem. 30: 1121-32.

[38] Doremus, R. H. 2002. "Optical Properties of Small Clusters of Silver and Gold Atoms." Langmuir 18: 2436-7.

[39] Busbee, B. D., Obare, S. O., and Murphy, C. J. 2003. “An Improved Synthesis of High-Aspect-Ratio Gold Nanorods." Adv. Mater. 15: 414-6.

[40] Horvath, H. 2009. "Gustav Mie and the Scattering and Absorption of Light by Particles: Historic Development and Basics." J. Quant. Spectrosc. Ra. 110: 787-99.

[41] Haiss, W., Thanh, N. T. K., Aveyard, J., and Fernig, D. G. 2007. "Determination of Size and Concentration of Gold Nanoparticles from UV-Vis Spectra." Anal. Chem. 79: 4215-21.
[42] Karakouz, T., Holder, D., Goomanovsky, M., Vaskevich, A., and Rubinstein, I. 2009. "Morphology and Refractive Index Sensitivity of Gold Island Films." Chem. Mater. 21: 5875-85.

[43] Scampicchio, M., Wang, J., Blasco, A. J., Arribas, A. S., Mannino, S., and Escarpa, A. 2006. "Nanoparticle-Based Assays of Antioxidant Activity." Anal. Chem. 78: 2060-3.

[44] Singh, A. K., and Srivastava, O. N. 2015. "One-Step Green Synthesis of Gold Nanoparticles Using Black Cardamom and Effect of $\mathrm{pH}$ on Its Synthesis." Nanoscale Res. Lett. 10: 353.

[45] Dhillon, G. S., Brar, S. K., Kaur, S., and Verma, M. 2012. "Green Approach for Nanoparticle Biosynthesis by Fungi: Current Trends and Applications." Crit. Rev. Biotechnol. 32: 49-73.

[46] MubarakAli, D., Thajuddin, N., Jeganathan, K., and Gunasekaran, M. 2011. "Plant Extract Mediated Synthesis of Silver and Gold Nanoparticles and Its Antibacterial Activity against Clinically Isolated Pathogens." Colloids Surf. B Biointerfaces 85: 360-5.

[47] Mittal, A. K., Chisti, Y., and Banerjee, U. C. 2013. "Synthesis of Metallic Nanoparticles Using Plant Extracts." Biotechnol. Adv. 31: 346-56. 